\title{
Bone Allografts in Dentistry: A Review
}

\section{Malinin $\mathrm{TI}^{1 *}$, Temple $\mathrm{HT}^{2}$ and $\mathrm{Garg} \mathrm{AK}^{3,4}$}

${ }^{1}$ Emeritus Professor of Orthopaedics, University of Miami Miller School of Medicine, Miami, FL, USA

${ }^{2}$ Professor of Orthopaedics and Director, Tissue Bank, University of Miami Miller School of Medicine, Miami, FL, USA

${ }^{3}$ Director, Center for Dental Implants of South Florida, Aventura, FL, USA

${ }^{4}$ Clinical Professor, University of Florida, School of Dentistry, Gainesville, FL, USA

\begin{abstract}
Transplantation of bone allografts is an accepted procedure in dentistry as it is in many surgical specialties. Despite wide acceptance and ready access to a number of bone allografts, there is often insufficient knowledge of the origin of these allografts and the processing methods. This brief review paper summarizes contemporary knowledge of the biologic properties of bone transplants used in dentistry and discusses their safety. It is intended to aid dental practitioners in selecting suitable bone allograft materials for their patients. It does not deal with bone autografts nor does it compare autografts and allografts. Long-term clinical results with allografts processed by different methods are also outside of the scope of this review.
\end{abstract}

Keywords: Bone allografts; Bone banking; Recipient safety; Freezedrying; Allograft sterilization; Allograft processing

\section{Introduction}

Dental practitioners perform more bone allograft transplants than any other surgical specialists. This development was made possible by the ready availability of bone allografts from a network of tissue banks [1-4]. Regretfully, the source of these grafts and the means of their preparation are not always apparent to many [5]. Too often bone allografts are ordered on the strength of the salesman's word or an advertisement. However, the sources of allografts, their preparation and their biological properties are important and present several complex issues. Thus, to obtain the optimal results with the grafting procedures and to safeguard recipients, it behooves the dental surgeon to possess full knowledge of the biologic properties of allograft bone, as well as its safety.

After the practicality of tissue banking was demonstrated by Kreuz et al. [6], Hyatt and Butler [7] and Malinin [8] and their associates, initial acceptance of allogeneic bone grafting was slow. However, once the advantages of allograft transplantation became apparent, the demand for allogeneic bone increased precipitously. This resulted in the proliferation of tissue banks with substantial variations in techniques of allograft excision and preparation. Attempts to standardize tissue banking by voluntary membership organizations have, by and large, resulted in failure since the standards were not mandatory and were formulated in compliance with the wishes of the tissue banks themselves $[9,10]$. Supervision by the FDA was and is still limited to the prevention of disease transmission with minimally manipulated donor tissues [11].

There are several methods by which bone allografts can be obtained and prepared. Some tissue banks use complex and stringent methods of excluding unsuitable donors from the donor pool. This is done by comprehensive donor screening and by rigorous disease surveillance using donor medical history, advanced laboratory methods, blood and marrow culture testing and post mortem examination. Under these circumstances, the risk of transmitting disease to the recipient is minimized. On the other hand, allografts obtained from donors about whom little is known, and whose medical status has not been ascertained present a problem.

Although cadaver bone has been transplanted with considerable success since the beginning of the last century, and in large numbers for the last several decades, the general sentiment that autografts are superior to allografts still prevails. However, this does not appear to be the case with allografts used in dental transplants.
The decision making process regarding allograft transplantation is a complex one, and must be based on a fundamental understanding of bone allograft biology. Once familiarity with the subject is gained, the dental practitioner will be in a position to determine whether or not transplantation of an allograft will be beneficial for a particular patient. To secure this advantage, knowing how allografts are obtained, processed and stored is necessary as well as knowing what types of allografts are available, and the general principles governing their behavior following transplantation.

\section{Postmortem Bone Donors}

Acceptance of tissue donors begins with a social and medical history. By necessity the history is based on secondhand information. A concerted effort to obtain and review available medical records will frequently provide information sufficient to accept or reject a donor. Both the Food and Drug Administration [FDA] and American Association of Tissue Banks [AATB] require exclusion from the donor pool of individuals in high risk behavior groups for acquiring infections with human immunodeficiency virus (HIV). Other infections which preclude bone donation are hepatitis $\mathrm{B}$ and $\mathrm{C}$ viruses and Treponema pallidum (syphilis). Individuals suspected of having or being exposed to Creutzfeld-Jacob Disease is also excluded.

The decision to become a tissue and organ donor can be made by the individual ante-mortem through motor vehicle licensing in select states. Permission is still required by the next of kin since the recovery agency requires indepth information about the donor's medical and social history. The FDA and AATB rely heavily on the information collected in this manner and without this vital information, recovery cannot proceed. However there are significant deficiencies, distortions and inaccuracies in obtaining information in this fashion. According to a study conducted by Young and Wilkins, and in our own experience,

*Corresponding author: Theodore Malinin, MD, University of Miami Miller Schoo of Medicine Tissue Bank [R-12], 1951 N.W. 7th Avenue, Suite 200, Miami, FL 33136, USA, Tel: 305-689-1403; E-mail: tmalinin @med.miami.edu

Received December 20, 2013; Accepted Janaury 21, 2014; Published January 23, 2014

Citation: Malinin TI, Temple HT, Garg AK (2014) Bone Allografts in Dentistry: A Review. Dentistry 4: 199. doi:10.4172/2161-1122.1000199

Copyright: $\odot 2014$ Malinin TI, et al. This is an open-access article distributed under the terms of the Creative Commons Attribution License, which permits unrestricted use, distribution, and reproduction in any medium, provided the original author and source are credited. 
information obtained in this manner might be inaccurate in as many as $50 \%$ of cases [12]. Because secondhand medical and social history is frequently unreliable, the FDA lists physical assessment of the cadaver donor and an autopsy, when it can be performed, as means of detecting the presence of relevant communicable diseases. An autopsy remains a reliable diagnostic method of uncovering and documenting pathologic conditions present in potential tissue donors, but it is not mandated for all donors. If an autopsy is performed, the information must be used in determining potential donor suitability.

Both the FDA and AATB do not specifically prohibit transplantation of tissues from donors with malignancies. This is left to the discretion of the Medical Director of the Tissue Bank. Although not a contraindication to recovery and processing, tissues from donors with malignancies are not consistent with good medical practice and the interests of the recipients. Both organizations reject, out of hand, suggestions that permission should be obtained from the recipient to accept a transplant from a donor with malignancy. Thus, an inquiry on this subject might be advisable before accepting an allograft from a tissue bank.

\section{Blood Serology}

To obtain pertinent information on a tissue donor, several serological tests are performed on the donor's blood. HIV-I and II antibodies are tested for as are antibodies to HTLV-1 and II and to hepatitis C virus. Serologic tests for hepatitis B antigen and antibodies are also performed. Polymerase chain reaction [PCR] is used to detect early HIV and hepatitis infections. Testing of blood for viral nucleic acids has reduced the undetectable window of infectivity [13]. Standard serologic tests for syphilis are also performed.

Because of the epidemic of acquired immunodeficiency syndrome [AIDS], patients have become justifiably concerned about the possibility of transmission of HIV by the graft. The AIDS epidemic prompted the American Academy of Orthopaedic Surgeons to be one of the first organizations to acknowledge the problem and to form a Task Force on AIDS and Orthopaedic Surgery. The report of the Task Force included recommendations for reducing the likelihood of HIV transmission through bone and tissue allografts [14]. With adequate safeguards, the risk of such transmission is low. With these in place, the risk of obtaining bone from an undetected HIV-infected donor has been calculated to be less than one in a million [15]. With the addition of tests for viral nucleic acids, the risk has been further reduced.

\section{Microbiology}

Microbiologic studies of cadaver bone donors are essential for determining graft suitability for transplantation

Since tissues from cadaver donors may harbor microorganisms, allografts excised from these donors cannot be assumed to be sterile, even if strict aseptic precautions are exercised. If microorganisms are present, they must be identified as well as the tissues involved. Blood and bone marrow cultures are helpful in predicting bone contamination. Positive blood and bone marrow cultures correlate with a higher rate of positive cultures from bone [30\%] as compared with positive blood [15\%] or marrow cultures [11\%] alone [16].

The source of microorganisms in cadaver blood is not always clear. Whether blood contamination occurs concurrently with the events leading to death, or whether it takes place postmortem has not been established [17]. The recovery of pathogenic bacteria at autopsy and the reported discrepancy between antemortem infection and postmortem culture results lead to the belief that microflora may be subject to agonal and postmortem dissemination. The time and sequence of such dissemination has not been defined [18]. That postmortem microbial contamination occurs within two or more days is unquestionable [19]. However, within 24 hours the only statistically significant difference between donors in which clostridia were detected and those not harboring these organisms is the interval between death and the excision of tissues [20]. Therefore the 24 hour limitation on excision of musculoskeletal tissue appears logical and prudent.

Clostridial infections transmitted by allografts have brought into focus the need for adequate donor microbiologic assessment requiring multiple tissue as well as blood and bone marrow cultures. Since the percentage of pathogenic microorganisms is relatively small, these can be detected reliably only when an adequate number of samples are tested. If this is not done, the extent of tissue contamination with dangerous microorganisms can be either underestimated, or missed altogether. Liquid cultures appear to be more sensitive in identifying bioburden than swab cultures [21].

\section{Autopsy}

Autopsy remains an accurate diagnostic modality for finding pathologic changes in cadaveric donors that might preclude transplantation of tissues. Numerous studies report significant discrepancies between the clinical diagnoses and postmortem findings [22-24]. Most studies report discrepancies in the neighborhood of $12 \%$. This figure has not changed significantly despite advances in imaging and other diagnostic techniques. In our experience, review of autopsy findings on over 5,000 consecutive bone and tissue donors showed major discrepancies between clinical diagnoses and autopsy findings in a significant number of cases.

\section{Excision of Bone Allografts}

Tissues must be excised within 24 hours postmortem if the donor's body had been refrigerated. If it is has not been refrigerated, excision of tissues is performed within 12 hours of death. The reason for this is that bacterial dissemination progresses rapidly after $24 \mathrm{hrs}$ of death. Methods of excision of bone have been described in detail elsewhere [25]. Ideally bone excision is performed in a clean room setting using standard aseptic surgical techniques. Repeated microbiologic monitoring is helpful and multiple samples are advisable (Figures 1 and 2). Whenever possible inoculation of tissue samples, rather than swabs cultures alone will improve recovery of microorganisms if present.

If a traditional operating room is not available, other rooms converted to a temporary operating room setting can produce the necessary aseptic environment although they are not ideal.

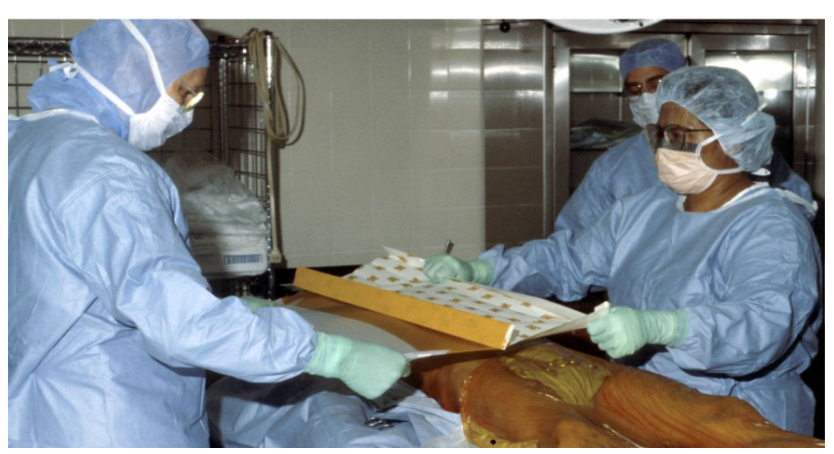

Figure 1: Excision of bone allografts from a cadaveric donor exercising aseptic technique in a dedicated clean room. 


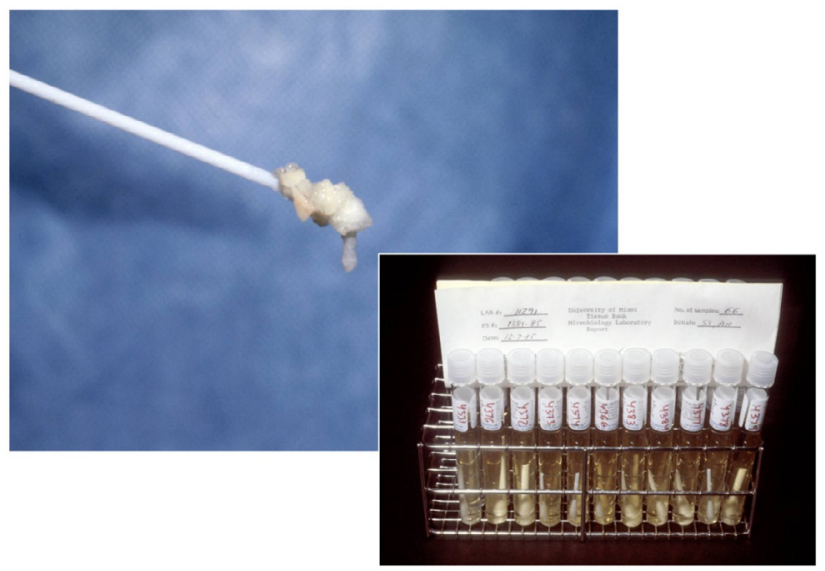

Figure 2: Multiple microbiologic sampling assures the sterility of recovered tissues.

In addition to the surgeon, at least two operating room technicians or nurses are needed for the recovery. One of these individuals' works on the back table, obtains culture samples, and wraps and packages the excised allografts. Another provides quality control, circulation and data entry functions.

\section{Preparation and Processing of Bone Allografts}

Bone allografts are usually processed in a separate facility. This allows for orderly handling of tissues and does not interfere with the excision process. However, some tissue banks excise and process allografts in the same room or suite of rooms. This is also acceptable and may be necessary for certain product lines. It is not ideal however as bacterial cross contamination is potentially increased.

After excision, individually packaged allografts are usually placed into a refrigerator overnight and are processed further after the results of serological studies, preliminary microbiologic cultures and the gross autopsy findings, if available, are known.

\section{Freezing of Bone}

Freezing to temperatures between -15 and $-20^{\circ} \mathrm{C}$ is easy and popular because it requires only the placement of the graft into generally available freezers. At this temperature ice crystals continue to grow and eventually destroy the bone making it soft. Therefore, by general consensus, bone can be maintained in the home-type freezers [about $-15^{\circ} \mathrm{C}$ ] for a limited time only. No exact data are available to indicate the maximum storage time for tissues maintained at these temperatures. Recommendations vary from 3 months to 1 year. Wilson reported a high failure rate with bone grafts stored for over a year at these temperatures [26]. Brown et al. reported satisfactory incorporation of bone grafts stored in such freezers for 6 months or less [27].

Temperatures lower than those of home-type freezers can be provided by solid carbon dioxide (dry ice) as well as by mechanical freezers, which operate at temperatures near $-79^{\circ} \mathrm{C}$, the melting point of dry ice. These temperatures are still not low enough to prevent the propagation of ice crystals.

For reliable long-term storage, it is necessary to employ very low [cryogenic] temperatures. Only at about $-120^{\circ} \mathrm{C}$ does the gradual growth of ice crystals cease completely. Temperatures below $-120^{\circ} \mathrm{C}$ can be obtained by the use of liquefied [cryogenic] gases, usually liquid nitrogen, or by specially designed low-temperature mechanical freezers. However, in dental practice, frozen allografts are not often used; only in rare cases where cartilage preservation is needed for temporomandibular transplantation for example. Therefore, consideration of cryopreservation and related topics is omitted from this review.

\section{Freeze-Drying}

Freeze-drying of bone allografts has been practiced for over 70 years. Although the process was described before World War II, it was not applied to human tissues until 1951 [6].

Freeze-drying is the application of a natural phenomenon of sublimation of water. In the atmospheric pressure below that of the vapor pressure of ice, drying takes place without melting of the ice. In the freeze-drying process the water is removed from the ice as vapor. Thus the ice from a frozen biologic structure disappears without melting and the water vapor is re-solidified on a colder surface.

Freeze-drying depends on unique properties of water, which has a melting point of $0^{\circ} \mathrm{C}$. It is not applicable to other chemical solutions. Thus, unless special devices and methods are employed, freeze-drying will remove only water from a biological object frozen in an aqueous chemical mixture. Other chemicals with boiling points different from that of water will remain as residues. Freeze-drying procedures are lengthy, but freeze-dried tissues can be stored and transported at room temperatures. However, changes produced in tissues by freezedrying are not insignificant. These have been attributed to alterations in protein configuration or the blocking of hydrophilic sites of proteins. ${ }^{[28]}$ On the positive side, these alterations are probably responsible for the reduction of antigenicity of freeze-dried bone. The exact mechanisms by which freeze-drying decreases the antigenicity and the sensitizing properties of bone are unknown, but the fact that it does so is well established.

Most of the original basic work on freeze-drying human bone was performed by the U.S. Navy Tissue Bank. Initially bone frozen to $-76^{\circ} \mathrm{C}$ was placed in the freeze-dryer chamber and allowed to warm to $0^{\circ} \mathrm{C}$ within the first 18 hours. The internal condenser was maintained at $-45^{\circ} \mathrm{C}$. After some 10 years, this technique was replaced by a 7 -day freeze-drying cycle in which the temperature of the allograft being freeze-dried was increased stepwise from $-40^{\circ}$ to $0^{\circ} \mathrm{C}$ over three days. This technique is still employed today, but modern freeze-dryers with external condensers have greatly improved the efficiency of the process [2].

A variation of the technique includes placement into freeze-dryer chambers of bone frozen in the vapor of liquid nitrogen. The condenser temperature is maintained at between $-60^{\circ} \mathrm{C}$ and $-70^{\circ} \mathrm{C}$. The vacuum in the freeze-dryer chamber is about 10-20 mTorr. The freeze-drying cycle is maintained from about 2 to 14 days. The discrepancies on the lengths of freeze-drying cycles depend on the efficiency of the apparatus, the amount of material placed in the chamber, and on different ways of measuring residual moistures [28,29].

Freeze-dried bone allografts should be rehydrated prior to implantation if preservation of biomechanical properties is desired. The importance of rehydration lies not only in the necessity to retain mechanical strength, but also in the resiliency of the grafts. However, in dental practice with particulate bone preparations rehydration is not important. Bone particles will become rehydrated by body fluids relatively quickly. 

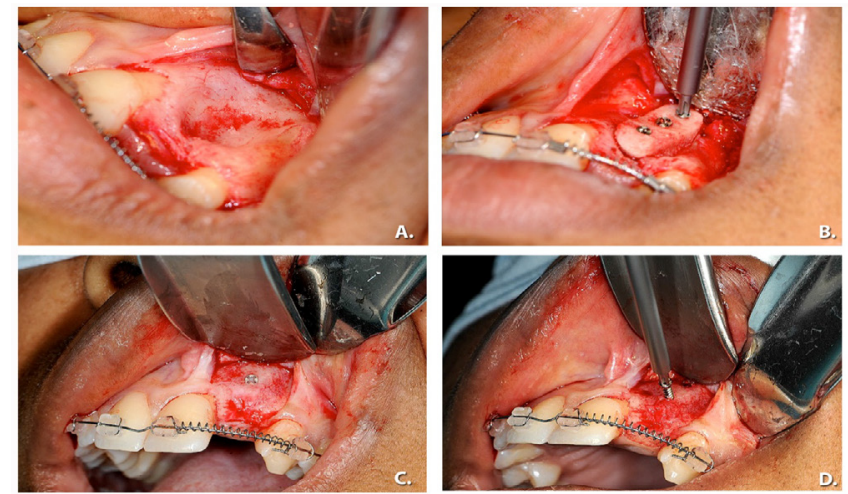

Figure 3: Reconstruction of mandibular and maxillary defects with freeze-dried structural allografts. (A.) Bone defect in area of tooth \#10. (B.) Bone allograft shaped to obliterate a defect and secured in place with screws. (C.) Grafted site uncovered after 5 months shows good healthy bone regeneration. (D.) Fixation screws removed for preparation of implant placement.

\section{Bone Allografts for Clinical Transplantation}

There are many varieties of grafting materials available. Freezedried allografts are the most common. When bone allografts which retain bone morphogenic proteins [BMP's] are placed in contact with vascularized host bone, they will unite with it and their calcified matrix will be replaced by new bone. The individual peculiarities of the human skeleton are such that each bone has its own requirements for healing, immobilization and bone grafting. Therefore, there is no universal, allpurpose bone allograft, and there is no single way of preparing all bone allografts. To date, in reconstructive dental surgery, the most successful bone allografts have been aseptically excised and processed freeze-dried cortical, cancellous and corticocancellous grafts which have not been subjected to extensive manipulations, such as exposure to chemical agents, heating, irradiation, ethylene oxide etc. [2].

Bone allografts commonly used in reconstructive dental procedures can be broadly divided into particulate and structural grafts. The former are used most frequently. Particulate grafts can be crushed cancellous or cortical bone [bone chips], ground bone, morselized bone or microparticulate grafts. These are used for filling defects with largely intact walls (closed intraosseous defects). The structural grafts are bone plates [bone struts], sections of mandibles and cortical and cancellous bone blocks. The former are used primarily to reconstruct large defects in bone (Figure 3).

\section{Chemical Sterilization}

The simplest method of preserving and sterilizing bone allografts at the same time would be by immersion into chemical solutions. Many of these, including ethyl alcohol have been tried though none have endured the test of time. When alcohol-fixed bone grafts were implanted into rodents, the bone was absorbed, but a few layers of new bone appeared in and around the grafts. Osteoclasts were absent at the periphery of alcohol-fixed grafts. Thus, it became evident that unlike boiling or autoclaving, the osteoinductive potential of the graft was not destroyed, but diminished to a great degree due to alcohol extraction [30]. When this alcohol extract was injected into rabbits, osteogenesis was induced in about one-third of the animals.

The boiled and alcohol-fixed grafts are mentioned here to demonstrate the differences of the recipient's response to bone transplants treated by different means. The aforementioned allografts, as well as allografts sterilized by immersion in several sterilizing solutions are still in use. There is little scientifically based information on the behavior of chemically sterilized bone allografts transplanted into humans. Unfortunately, this has resulted in the empirical development of methods for bone allograft preparation by trial and error. Virtually everything was tried, but the only two methods of secondary sterilization which withstood the test of time are irradiation and sterilization with ethylene oxide gas.

\section{Irradiation}

The reason for irradiating bone allografts is the fear of transmission of infections, including those caused by HIV and the avoidance of the time, expense and expertise required for aseptic excision and processing of bone. Irradiation is ineffective against prions, and thus cannot prevent transmission of Creutzfeld-Jacob disease. Relatively high doses of irradiation are needed to inactivate HIV in bone, but the actual dose estimates vary. Although a 15 to $25 \mathrm{kGy}$ dose is commonly used, Conway et al. stated that $15 \mathrm{kGy}$ would not reliably inactivate HIV in bone [31]. Doubling the dose to $30 \mathrm{kGy}$ may be necessary. Irradiation in this range alters the biomechanical integrity of the graft [32] and reduces its osteoinductive potential $[33,34]$.

The choice of using irradiated allografts is based on personal experience, training and the availability of the grafts. It must be balanced between the reduction of the risk of infection with aseptic processing only and the undesirable side effects of irradiation. The subject of irradiation of bone allografts is controversial. On one hand there are those who feel irradiation has no place in allograft preparation while others are willing to accept irradiated allografts despite reduction of the osteogenic potential in these grafts. Bone is made brittle by irradiation because of the destruction of collagen alpha chains [35]. Irradiation of bone while frozen partially mitigates the undesirable effects of irradiation [36]. However, the osteoinductive potential in irradiated bone is reduced compared to that of non-irradiated bone (Figure 4).

\section{Ethylene Oxide Sterilization}

Ethylene oxide (ETO) not only sterilizes the air, but penetrates many types of material such as paper, cloth and cellophane. It has bactericidal and virucidal properties [37-40]. Variation in resistance to ethylene oxide among spore forming organisms such as Clostridria has been also noted.

When tissues are sterilized with ethylene oxide, its secondary products, ethylene glycol [EG] and ethylene chlorohydrin [ECH] remain. These residues, in high enough concentrations, cause hemolysis and inflammation. For this reason, the FDA had published a limit
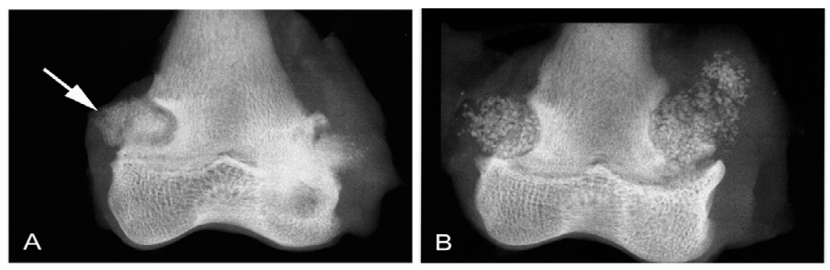

Figure 4: A. Irradiated (25kGy) particulate cortical bone allograft (500 to 800 $\mu \mathrm{m}$ ) six weeks post transplantation into an experimental animal. The allograft (arrow) remained virtually intact with very little bone formation in the periphery of the defect. This indicates absence of active osteogenesis. B. Irradiated (25kGy) demineralized cortical bone allograft $(500-800 \mu \mathrm{m})$, six weeks after transplantation into an experimental animal. Active osteogenesis is absent as observed in the irradiated non-demineralized graft. 
for the quantity of these compounds remaining on the implantable materials [41] a requirement that recently has been rescinded. In general, sterilization of bone allografts with ethylene oxide renders these free of active infectious agents, bacterial, fungal or viral [42]. The presence of ethylene oxide residuals in allografts is toxic to fibroblasts, but these effects can be mitigated by thorough, controlled washing of the allografts [43]. Although sterilization with ETO is very effective it is now not used very often because of the environmental regulations, required validation studies and high material costs.

\section{Biology of Bone Transplants}

Many types of bone allografts have been studied experimentally and clinically. Since osteocytes in transplanted bone are dead, the grafts themselves do not contribute cells to osteogenesis. The basis for the complex activity resulting in the new bone formation is the stimulation and recruitment of the recipient's mesenchymal cells. These induce osseous bridging at the host-graft interface and gradually replace the graft. To be effective, bone allografts must possess osteoinductive properties that are maintained by some methods of preservation, reduced by some and destroyed by others.

Boiling was one of the earliest methods of preserving bone. Early on it was shown that boiled bone was non-osteogenic and was absorbed extremely slowly. According to Lacroix, at seven months posttransplantation, boiled animal bone allografts remained almost intact. Autoclaved bone has been observed to behave in a similar fashion [30].

Morphologic analysis of allogenic bone grafts removed from patients before complete healing shows these to be acellular, but surrounded by mesenchymal tissue, which undergoes metaplasia and ossification. This basically outlines the entire spectrum of bone allograft interaction with the host. Aside from temporal considerations, no quantitative differences in osseous incorporation have been noted between autografts and freeze-dried allografts, as both biologic materials go through revascularization, osteoclastic resorption, new bone formation and remodeling.

The response to allograft implantation is modified by processing, which may include irradiation, exposure to chemicals, etc. Exposure to hydrogen peroxide diminishes or abolishes the osteogenic potential of the graft [44].

The clinical acceptance of freeze-dried bone allografts is based on the reduced immunogenicity of these preparations [45]. The reason for the latter is most likely the removal of antigen presenting cells which reside in the trabeculae within bone marrow [46] as well as alterations in bone collagen.

\section{Particulate Bone Allografts}

Particulate bone allografts have been used to fill cavitary and periprosthetic defects for the last two decades with considerable clinical success $[47,48]$. Radiographically graft incorporation is observed in over $90 \%$ of patients. Complications are few. However, despite clinical success with particulate allografts, ideal properties of these grafts were ill-defined until recently. Consequently, tissue banks prepare particulate allografts in different sizes and forms and by a variety of methods. Recently, it became clear that one parameter that warrants attention is the size of the particle itself. The size bears relation to osteoinduction and osteoconduction. Osteoinduction depends on the biological property of the graft reflected by its ability to stimulate ingrowth of neovasculature, mobilize the mesenchymal cells of the host, and transform these into osteoprogenitor cells. This process is mediated by the release of various growth factors, principal of which are

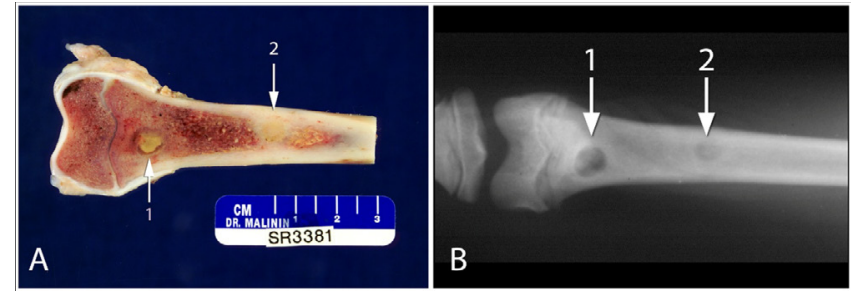

Figure 5: Defects in the cortical and cancellous bone in an experimental animal six weeks post allografting. A-gross specimen. B -AP radiograph. The defect indicated by the arrow \#2, filled with microparticulate bone particles (150 to $125 \mu \mathrm{m}$ ) healed completely. The defect \# 1, filled with microparticulate bone particles $(75-53 \mu \mathrm{m})$ remained largely unhealed.

bone morphogenetic proteins [BMPs]. To be effective, BMP's must be present in pharmacological quantities [49]. In addition, BMP's depend for transport on intraosseous lipid, which facilitates delivery of BMP to the site [50]. Ideally, for dental applications, particulate allografts, in addition to being osteoinductive, must be also osteoconductive. They must provide direct opposition between the graft and the host, and in addition to mechanical support allow for ingrowth of newly formed bone. Densely packed bone particles of appropriate sizes satisfy both of these requirements [51].

Washing of the graft and removal of bone marrow and extraosseous fat allows for compacting of the graft material in the defect [52].

In laboratory experiments, bone allografts with particles of different sizes showed clear cut differences in the healing patterns and osteogenic properties (Figure 5). Particles in the range of the 300 to 90 microns produce rapid healing by direct ossification. Particles below 90 microns have significantly reduced osteoinductive potential. Particles larger than 300 microns were much slower in healing and incorporation than 300 to 90 micron particles. Small-sized powdery bone particles below 75 microns induce little osteogenesis similar to small particles of hydroxyapatite which in fact, inhibit osteoclastic activity [53]. Because of these undesirable properties of powdered preparations, the term "bone powder" should not be applied across the board. Powder means a dry substance composed of minute dust-like particles, precisely the composition which does not enhance osteogenesis. For this reason, and to delineate bone particle sizes most effective in inducing bone healing, the term "microparticulate bone allograft" is more descriptive and preferable. It clearly delineates particulate compositions between small granules and powders.

Frozen microparticulate allografts lag considerably behind their freeze-dried counterparts in inducing bone healing. [54] Thus, from practical consideration, freeze-dried microparticulate allografts appear to be most suitable for use in dentistry.

Cortical bone when implanted as a solid structure exhibits a different pattern of incorporation than do cancellous structural grafts however, with particulate allografts there is no difference between cortical and cancellous bone preparations since the basic structure of cancellous bone trabeculae and bone cortex is the same [55].

\section{Demineralized Particulate Bone}

There exists considerable confusion with regard to demineralized bone matrix $[\mathrm{DBM}]$ and demineralized, or more precisely, partially decalcified bone. The methods of preparation of these allografts are distinct, as are their biological properties. DBM is prepared by simply demineralizing bone in hydrochloric acid [usually INHCI] until the calcium content is reduced to less than $2 \%$. Since DBM is prepared 
from particulate bone, its preparation frequently entails freeze-drying the bone, grinding it, demineralizing it, and refreeze-drying it again. Thus in contradistinction to other freeze-dried bone allografts, DBM is freeze-dried twice. DBM is grossly amorphous, soft and does not provide structural support.

Demineralization is said to increase availability of bone matrixassociated bone morphogenetic proteins [BMP's] rendering these grafts osteoinductive. However, it must be noted, non-demineralized particulate grafts are also osteoinductive. There seems to be little difference in clinical results between demineralized and nondemineralized particulate allografts [56]. Thus extra effort and expense of using demineralized bone matrix may not be fully justified. Although demineralization releases BMP from bone, it also facilitates BMP elution and loss into the acid bath [57]. Furthermore, other potentially antigenic proteins may be exposed eliciting an immune response that may result in inflammation and rapid graft resorption. Partially demineralized, partially decalcified or surface decalcified bone is exemplified by Urist's chemosterilized, antigen-extracted allogeneic [AAA] bone [58]. Preparation of this allograft is complex and timeconsuming, but its clinical efficacy has been documented [56].

The calcium content of AAA bone is in the neighborhood of 10 to $15 \%$. The calcium content of surface demineralized bone allograft is somewhat higher, usually around $20 \%$. Both of these types of preparations maintain osteoconductive properties.

\section{Bleached Bone}

A number of commercial bone allograft distributors promote allografts on the basis of their whiteness. As everyone knows, normal bone is not white, but grayish, brownish or yellowish. Chalk white bone is bleached. There is no reason to bleach bone allografts other than for the sake of cosmetic appearance. Bleaching is usually achieved by bathing allografts in a solution of hydrogen peroxide $\left[\mathrm{H}_{2} \mathrm{O}_{2}\right]$. Exposure to $\mathrm{H}_{2} \mathrm{O}_{2}$ diminishes or abolishes osteoinductivity [44], but the effect is time-dependent $[59,60]$. This is balanced against disinfecting activity of the compound. According to Holzclaw et al., one hour exposure to $\mathrm{H}_{2} \mathrm{O}_{2}$ does not have a profound effect on osteoinduction by bone allografts [60].

\section{Discussion}

Review of bone banking was undertaken to aid dental practitioners in distinguishing a variety of methods employed in bone allograft preparation. Bone grafting in large measure depends on dental practitioners themselves. Clinical success also hinges on knowledge of the types of grafts, their optimal function and the means by which they are recovered and processed.

Current practices have evolved from trial and error, observation, laboratory studies and clinical results. Relatively sudden demand for allografts did not allow for step-wise progression of the development of tissue banking. Pieces of information from disjointed laboratory studies and clinical experiences, when these became available, influenced the development of the currently used techniques. Several tissue banks adopted proprietary techniques and methodology for allograft preparation. These were promoted mainly through advertising without adequate data published in scientific literature substantiating the claims. In preparing this review, discussion of unsubstantiated claims and general statements were avoided. Instead, well-established principles and findings were brought to the reader's attention so that this information could assist them in making informed judgments regarding what type of allografts to transplant in patients. Laboratory studies help to predict the behavior of grafts transplanted into humans, but we must keep in mind the differences between laboratory animals, particularly rodents, and humans.

The use of bone allografts in filling periodontal, mandibular and maxillary defects is now an accepted, commonly used procedure. However, the optimal method of allograft bone preparation is still a subject of some debate. Proponents of demineralized bone particles cite the improved biological characteristics of the material. Clearly considerable clinical success has been reported with DBM. However, bone particles of defined sizes likewise produce adequate bone healing and allograft incorporation whether they are demineralized or nondemineralized. Most frequently used allografts are those of particulate bone especially in sinus graft procedures and ridge augmentations.

Allograft safety is of course, of great concern to all dental practitioners as well as their patients. Relatively recent media reports concerning inappropriately acquired human tissues have shaken public confidence in the tissue allografts. This prompted the Journal of the American Dental Association to publish a review on the safety of bone allografts used in dentistry [61]. The article concluded: "when purchasing human bone allografts for the practice of dentistry, one should choose products accredited by the American Association of Tissue Banks for meeting uniformly high safety and quality control measures." The statement is not entirely correct. First of all AATB accredits tissue banks, not the product they produce. Secondly the tissue banks who used the services of Biomedical Tissue Services which precipitate the above mentioned scandal were AATB accredited. For that matter Biomedical Tissue Services were inspected by the FDA. This makes it clear that inappropriate and dangerous practices can take place despite inspections and accreditations. Therefore it behooves dental practitioners to satisfy them with regard to the integrity of tissue banks from which they obtain allografts, and the quality of the grafts they receive.

The ever increasing demand for bone allografts attests to the clinical usefulness of these grafts. Obtaining bone allografts from the institution which adheres to safe and reliable measures in providing human tissues for transplantation will alleviate the concerns of the dental practitioner with regards to their patients' safety and the clinical efficacy of the graft.

\section{References}

1. Kozak JA, Heilman AE, O'Brien JP (1994) Anterior lumbar fusion options; techniques and graft materials. Clin Orthop Relat Res 200: 45-51.

2. Malinin TI, Temple HT (2013) Musculoskeletal Tissue Transplantation \& Tissue Banking. Jaypee Bros Medical Publishers, LTD, New Delhi, London, Philadelphia, Panama.

3. Mankin HJ, Doppelt S, Tomford WW (1983) Clinical experience with allograft implantation. Clin Orthop Relat Res 174: 69-72.

4. Emerson RH Jr, Malinin TI, Cuellar AD, Head WC, Peters PC (1992) Cortical strut allografts in the reconstruction of the femur in revision total hip arthroplasty: a basic science and clinical study. Clin Orthop Relat Res 285: 35-44.

5. Lavernia Cl, Malinin TI, Temple HT, Moreyra CE (2004) Bone and tissue allograft use by orthopaedic surgeons. J Arthroscopy 19: 430-433.

6. Kruez FP, Hyatt GW, Turner TC, Bassett AJ (1951) The preservation and clinical use of freeze dried bone. J Bone Joint Surg Am 33: 863-872.

7. Hyatt G, Butler MC (1957) Bone grafting; the procurement, storage and clinical use of bone allografts. Instr Course Lect 14: 343-373.

8. Malinin TI (1976) University of Miami Tissue Bank: Collection of postmortem tissues for clinical use and laboratory investigation. Transpl Proc 8: 53-58.

9. South-Eastern Organ Procurement Foundation (1985) Guidelines and Standards for excision, preparation and distribution of human tissue allografts for transplantation. Richmond, VA. 
10. American Association of Tissue Banks (1984) Standards for Tissue Banking McLean, VA.

11. U.S. Food and Drug Administration (2004) 21 CFR.

12. Young SE, Wilkins RM (1995) Medical/Social history questionnaires; validating the process. Proc. $19^{\text {th }}$ Annual Mtg. American Association of Tissue Banks. Atlanta, GA.

13. Strong M, Nelson K, Pierce M, Stramer SL (2005) Preventing disease transmission by deceased tissue donors by testing blood for viral nucleic acid. Cell Tissue Bank 6: 249-253.

14. American Academy of Orthopaedic Surgeons Task Force (1989) AIDS and Orthopaedic Surgery. AAOS, Park Ridge, IL.

15. Buck BE, Malinin TI, Brown MD (1989) Bone transplantation and human immunodeficiency syndrome [AIDS]. Clin Orthop Relat Res 240: 129-136.

16. Martinez OV, Buck BE, Hernandez M, Malinin TI (2003) Blood and marrow cultures as indicators of bone contamination in cadaver donors. Clin Orthop Relat Res 409: 317-324.

17. DuMolin G, Love W (1982) The value of autopsy microbiology. Clin Microbio Newsletter 10: 165-167

18. Koneman E, Davis M (1974) Postmortem bacteriology 3. The significance of microorganisms recovered at autopsy. Am J Clin Path 61: 28-40.

19. Roberts FJ (1998) Procurement, interpretation and value of postmortem culture. Eur J Clin Microbiol Infec Dis 17: 821-827.

20. Malinin TI, Buck BE, Temple HT, Martinez OV, Fox WP (2003) Incidence of clostridial infection in donors' musculoskeletal tissues. J Bone Joint Surg 85 1051-1054.

21. Dennis JA, Martinez OV, Landy DC, Malinin TI, Morris PR, et al. (2011) A comparison of two microbial detection methods used in aseptic processing of musculoskeletal allograft tissues. Cell Tissue Bank 12: 45-50.

22. Chacon M, Gazitua R, Paebla C (1997) Clinical correlation between the premortem study and autopsy. Rev Med Chil 125: 1173-1176.

23. Thurlbeck WM (1981) Accuracy of clinical diagnosis in a Canadian teaching hospital. Can Med Assoc J 125: 443-447.

24. Friedrici HH, Sebastian M (1984) Autopsies in a modern teaching hospital. A review of 2,537 cases. Arch Pathol Lab Med 108: 518-521.

25. Malinin TI (1993) Allografts for the reconstruction of the cruciate ligaments of the knee: Procurement, sterilization and storage. Sports Med \& Arthroscopy Rev 1: 31-41.

26. Wilson PD (1951) Follow-up study of the use of refrigerated homologous bone transplants in orthopaedic operations. J Bone and Joint Surg 33: 307-323.

27. Brown MD, Malinin TI, Davis PB (1976) A roentgenographic evaluation of frozen allografts versus autografts in anterior cervical spine fusions. Clin Orthop Relat Res 119: 231-236.

28. Greiff D (1973) The important variables in the long-term stability of viruses dried by sublimation of ice in vacuo. Progress in refrigeration science and technology. Proceedings of the XIII Int'l Congress of Refrigeration. AVI Publishing Co, Westport.

29. Malinin TI, Wu NM, Flores A (1983) Freeze drying of bone for allotransplantation. Little Brown \& Co., Boston/Toronto.

30. Lacroix P, L'Organisacion des OS (1949) Editions Desoer, Liege.

31. Conway B, Tomford WW, Hirsch MS, Schooley RT, Mankin HJ (1990) Effects of gamma radiation on HIV-1 in a bone allograft model. Trans 36 Annual Meeting Orthop Res Soc 15: 225

32. Gibbons MJ, Butler JH, Grood ES, Bylski-Austrow DI, Levy MS, et al. (1991) Effects of gamma irradiation on the initial mechanical and material properties of goat bone-patella tendon-bone allografts. J Orthop Res 9: 209-218.

33. Buring K, Urist MR (1967) Effect of ionizing radiation on the bone induction principle in the matrix of bone implants. Clin Orthop Relat Res 55: 225-234.

34. Urist MR, Hernandez A (1974) Excitation transfer in bone. Arch Surg 119: 486493

35. Hamer AJ, Colwell A, Eastell R (1995) Biomechanical and biochemical changes in cortical bone after gamma irradiation. J Bone Min Research 10: 339.
36. Hamer AJ, Stockley I, Elson RA (1999) Changes in allograft bone irradiated at different temperatures. J Bone Joint Surg 81: 342-344.

37. Kerulek K, Gammon RA, Lloyd RS (1970) Microbiological aspects of ethylene oxide sterilization. II. Microbial resistance to ethylene oxide. App Microbiol 19: 152-156.

38. Klaienbeek A, Van Torngen HAE (1954) Virucidal action of ethylene oxide. J Hyg 52: 525-528.

39. Sidwell RW, Dixon GJ, Westbrook L, Dulmadge EA (1969) Procedure for the evaluation of the virucidal effectiveness of an ethylene oxide gas sterilizer. App Microbiol 17: 790-796.

40. Prolo DJ, Pedrotti PW, White DJ (1980) Ethylene oxide sterilization of bone dura mater and fascia lata for human transplantation. Neurosurg 6: 529-539.

41. Gardner S (1978) Ethylene oxide, ethylene chlorohydrin and ethylene glycol Proposed maximum residue limits and maximum levels of exposure. Fed Reg 43: 27474-27483.

42. Moore T, Gendler EL, Gendler E (2004) Viruses absorbed on musculoskeleta allografts are inactivated by ethylene oxide disinfection. J Orthop Res 22: 13581361.

43. Arizono T, Iwamoto Y, Okuyama K, Sugioka Y (1994) Ethylene oxide sterilization of bone grafts: residual gas concentration and fibroblast toxicity. Acta Orthop Scan 65: 640-642.

44. Carpenter ET, Gendler E, Malinin TI, Temple HT (2006) Effect of hydrogen peroxide on osteoinduction by demineralized bone. Am J Orthop 35: 562-567.

45. Horowitz MC, Friedlaender GE (1987) Immunologic aspects of bone transplantation: A rationale and future studies. Orthop Clin North Am 18: $227-$ 233.

46. Czitrom AA, Axelrod T, Fernandes B (1985) Antigen presenting cells in allotransplantation. Clin Orthop Relat Res 197: 27-31.

47. Sloof TJ, Buma P, Schreurs BW, Schimmel JW, Huiskes R, et al. (1996) Acetabular and femoral reconstruction with impacted graft and cement. Clin Orthop Relat Res 324: 108-115.

48. Temple HT, Malinin TI (2008) Microparticulate cortical allograft: an alternative to autograft in the treatment of osseous defects. Open Orthop J 2: 91-96.

49. Urist MR, Sato K, Brownell AG, Malinin TI, Lietze A, et al. (1983) Human bone morphogenetic protein [hBMP]. Proc Soc Exp Bio Med 173: 194-199.

50. Urist MR, Benham K, Krendi F, Raskin K, Nguyen TD, et al. (1997) Lipids closely associated with bone morphogenetic protein [BMP] and induced heterotopic formation. Connect Tissue Res 36: 9-20.

51. Malinin TI, Carpenter EM, Temple HT (2007) Particulate bone allograft incorporation in regeneration of osseous defects; importance of particle sizes. Open Orthop J 1: 19-24.

52. Dunlop DG, Brewster NT, Madabhushi SP, Usmani AS, Paukaj P, et al. (2003) Techniques to improve the shear strength of impacted bone graft: the effect of particle size and washing the graft. J Bone Joint Surg 85: 639-646.

53. Sun JS, Liu HC, Chang LH, Li J, Lin FH, et al. (1998) Influence of hydroxyapatite particle size on bone cell activities; an in vitro study. J Biomed Materials Res 39: 390-397.

54. Malinin TI, Temple HT (2007) Comparison of frozen and freeze dried particulate bone allografts. Cryobiology 55: 167-170.

55. Malinin TI, Temple HT, Garg A (2009) Cancellous and cortical microparticulate allograft for dental implantation: an experimental study in non-human primates. Implant Dentistry 18: 420-426.

56. Cammack GV 2nd, Nevins M, Clem DS 3rd, Hatch JP, Mellonig JT (2005) Histologic evaluation of mineralized and demineralized freeze-dried bone allograft for ridge and sinus augmentations. Int J Periodontics Restorative Dent 25: 231-237

57. Pietrzak WS, Ali SN, Chitturi D, Jacob M, Woodell-May JE (2009) BMP depletion occurs during prolonged acid demineralization of bone: characterization and implication for graft preparation. Cell Tissue Bank 12: 81-88.

58. Urist MR (1983) Chemosterilized antigen-extracted surface demineralized allogeneic bone for arthrodesis. Little Brown \& Co, Boston.

59. DePaula CA, Truncale KG, Gertzman AA, Sunwoo MH, Dunn MG (2005) Effect of hydrogen peroxide cleaning procedures on bone graft osteoinductivity and mechanical properties. Cell Tissue Bank 6: 287-298. 
60. Beebe KS, Benevenia J, Tuy BF, DePaula CA, Harten RD, et al. (2009) Effect of new allograft processing procedure on graft healing in a canine model. Clin Orthop Relat Res 467: 273-280.
61. Holzclaw D, Toscano N, Eisenlohr L, Callan D (2008) The safety of bone allografts used in dentistry. J Am Dent Assoc 139: 1192-1199. 